\title{
Erratum to: Down-regulation of miR-181a can reduce heat stress damage in PBMCs of Holstein cows
}

\author{
Kun-Lin Chen ${ }^{1} \cdot$ Yuan-Yuan $\mathrm{Fu}^{1} \cdot \mathrm{Min}-\mathrm{Yan} \mathrm{Shi}^{2} \cdot \mathrm{Hui}-\mathrm{Xia} \mathrm{Li}^{1}$
}

Published online: 14 November 2016

(C) The Society for In Vitro Biology 2016

Erratum to: In Vitro Cell. Dev. Biol.-Animal

DOI 10.1007/s11626-016-0045-x

Published Vol 52:864-871

In the Acknowledgments paragraph on page 869, the correct foundation number for the Natural Science Foundation of Jiangsu Province is BK2012368.

The online version of the original article can be found at http://dx.doi. org/10.1007/s11626-016-0045-x.

Hui-Xia Li

li.huixia@yahoo.com

1 College of Animal Science and Technology, Nanjing Agricultural University, Nanjing 210095, China

2 Luoyang Normal University, Luoyang, Henan Province 471000, China 